\title{
Rehabilitation implant supported in malocclusion class II with high need for lip support: case report
}

\begin{abstract}
Hybrid prosthesis is a feasible treatment in Patients With malocclusion type II. The present article shows a case report of a female patient Who Had many teeth extractions of the upper teeth and an Denture immediate, followed by a fixed full arch prosthesis over six implants, while in the jaw, the multiple teeth extraction and the installation of a fixed prosthesis and a splint protection. This article describes step by step the complete patient rehabilitation in a type II malocclusion with an esthetic and functional point of view.
\end{abstract}

Keywords: implant prosthetics, hybrid prosthetics, prostheses and implants, malocclusion
Volume 9 Issue 4 - 2018

\author{
Pedro Borja Pantoja Estephano,' Over Silvio \\ Requena Cisneros, ${ }^{2}$ Graciela Echeverria \\ Geldres, ${ }^{3}$ Matta Carlos Morales ${ }^{4}$ \\ 'Departmnet of Medicine, Dentistry and Nursing, Cayetano \\ Heredia University, Peru \& Dentist, International University of \\ Ecuador, Ecuador \\ ${ }^{2}$ Specialist, Cayetano Heredia University, Peru \\ ${ }^{3}$ Dentist \\ ${ }^{4}$ Dental surgeon, Oral Rehabilitation specialist, Cayetano \\ Heredia University, Peru
}

Correspondence: Estephano Pedro Borja Pantoja,

Departmnet of Medicine, Dentistry and Nursing, Cayetano

Heredia University, Peru \& Dentist, International University of

Ecuador, Ecuador, Julio C, Tello 650, Lima, Peru,

Email pedro.pantoja.b@upch.pe

Received: June 01, 2017 | Published: August 08, 2018

\section{Introduction}

Fixed prosthetic rehabilitation and supported implant has become the last decade in an alternative treatment in edentulous patients. Conventional restorations as removable prostheses can be a limitation for many people the lack of retention and stability due to poor bone support that is affected by an inevitable process of bone resorption. Bone resorption is a problem that denture wearers face and therefore often need constant adjustment, exceeded even replacements Dentures. ${ }^{2}$ Dental implants have a $98 \%$ survival and thus become an excellent alternative for rehabilitating a patient in edentulous areas to return masticatory function and aesthetics. ${ }^{3}$ While today almost all patients may be candidates for implants performed, it is essential to have some requirements that allow adequate osseointegration and future success of rehabilitation. ${ }^{4}$ The hybrid prosthesis is a prosthetic implant supported composed of a combination of different materials: metallic structure, acrylic teeth and acrylic resin. ${ }^{5}$ Before the making the hybrid prosthesis need to evaluate lip support, prosthetic space, arc-shaped prosthesis design, keratinized tissue, bone quantity and quality, and patient expectations cantilever. ${ }^{1-4}$ The lip support needs to be previously evaluated because it influences the position of the anterior teeth. ${ }^{1}$ Another key point is the prosthetic space, for which Mish et al 2008 proposes a interacada space between $11 \mathrm{~mm}$ to $15 \mathrm{~mm}$ indicated in a hybrid prosthesis, which will be distributed to the acrylic resin, metal structure, acrylic teeth and space free between the gum. ${ }^{4}$ Furthermore, Drago in 2012 proposes a design space using hybrid prostheses: $1 \mathrm{~mm}$ between gingiva and structure $2 \mathrm{~mm}$ acrylic resin, $6 \mathrm{~mm}$ metallic base $2 \mathrm{~mm}$ acrylic resin. ${ }^{6}$ This article describes the complete oral rehabilitation using dental implants by clinical analysis, this being the essential part of the diagnostic test for proper treatment. The objective of the case report was to return an appropriate aesthetics and masticatory function the patient. The case report will serve to share new information and experience during the clinical care of the patient, information that can be useful for the health team.

\section{Clinical case}

\section{Overview and stomatologic}

Female patient 64 years old, in good general condition, arrives at the Graduate Oral Rehabilitation, Faculty of Medicine, Dentistry and Nursing at the Universidad Peruana Cayetano Heredia. The chief complaint of the patient was: "I come to put myself implants, I cannot eat and I look bad teeth". Clinical examination to dentistry filed a class II malocclusion. In the upper jaw fixed prostheses was observed in poor condition parts with mobility grade II and III, as well as radicular remains and exostosis of the alveolar ridge. In the lower jaw presented slight attrition in the lower anterior sector mobility, fixed prosthesis shabby root remnant and absence of other teeth (Figure 1) (Figure 2). In the panoramic radiograph the maxillary with mild bone resorption, previous treatments ducts with radiolucent apical areas and poorly adapted prostheses was observed (Figure 3).

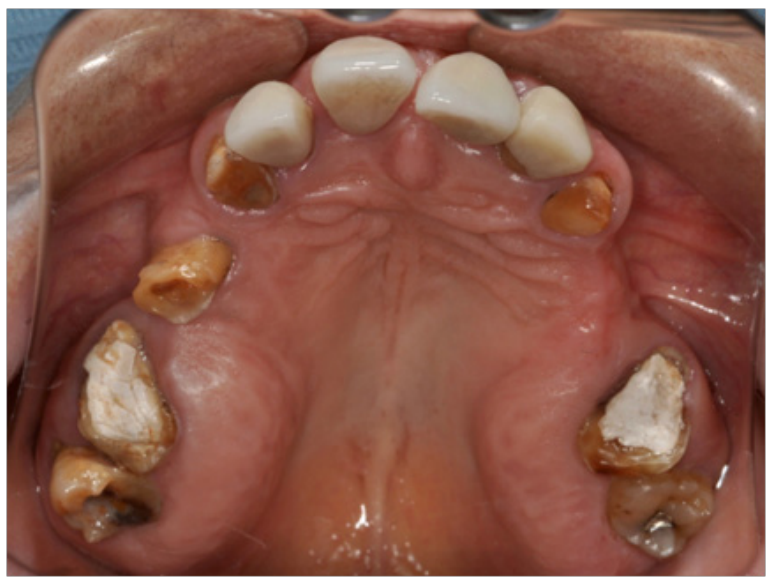

Figure 1 


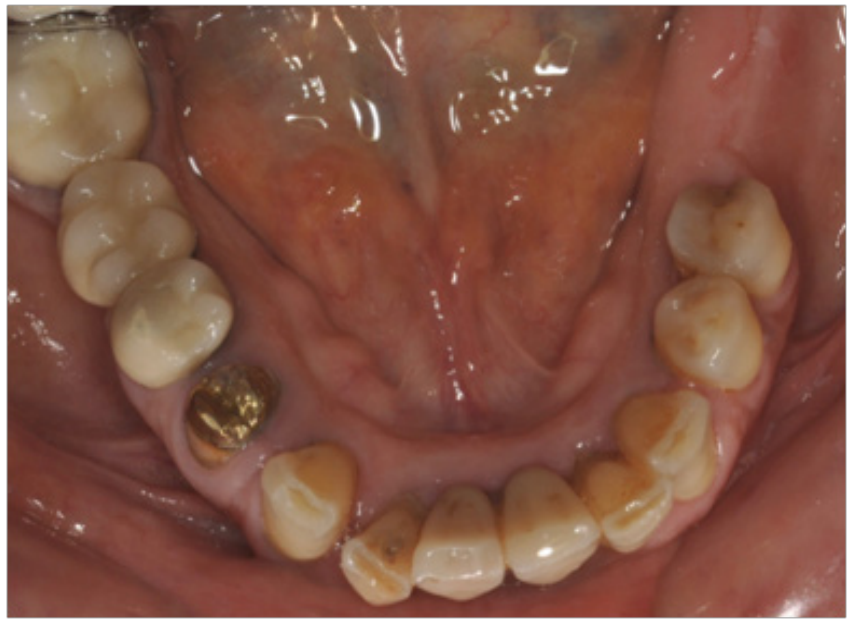

Figure 2

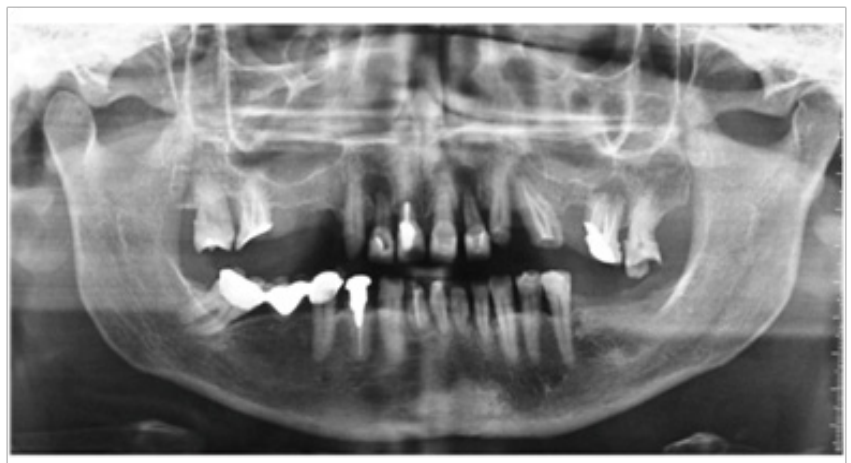

Figure 3

\section{Diagnosis}

The general diagnosis of the patient was: Female patient 62 years old with good condition. Stomatological diagnosis of conditions was:

1. Periodontal: Generalized Chronic Periodontitis.

2. Dental tissues: Multiple Caries and attrition, 3. Occlusion: Posterior bite collapse.

\section{Treatment}

Protesis top bottom provisionalization immediately: In the upper jaw removal of all teeth due to poor prognosis they had, followed by the preparation of an immediate prosthesis with use of fabric conditioner it was made. He was told the patient wearing the prosthesis for 24 hours; this is for the healing of tissues according to the shape of the denture base occurs. Control at 24 hours and then the removal of stitches at 7 days were performed (Figure 4). In the lower jaw bridge was removed, the extractions were performed; the root canals and installing were made spigots. After the defocusing, the parts 33, 43, 45, 47 were cut, and printing was made with condensation silicone Zetaplus ${ }^{\circledR}$ and Oranwash L ${ }^{\circledR}$ (Zhermack, Badia, Italy) for making provisional thermosetting.

Protesis 1.2 hybrid: After six months of healing, a new full denture was made. In this process, the base plate and the impeller has a key for assessing soft tissue support role, determine the vertical dimension, and measure the prosthetic space available for the preparation of the implant prosthesis. Threading the prosthesis it was duplicated for making a tomographic guide, in which gutta percha markers were placed both labially for the prosthetic contour, and the likely routes of future implant insertion. These markers were used to perform the analysis in the tomographic study and perform surgical planning and prosthetic implants in areas of the pieces 15,13,11,21,23,25 (Figure 5). After 4 months the angulation of the pillars and depth of transmucosal abutment with the tester was evaluated. The employees were pillars Pillars Mini CM Recto (Neodent) for parts 13,11,21 and 23, and angulated conical minipilares $17^{\circ}$ ( Neodent) for parts 15 and 25 , which torquearon according to manufacturer (32N and $15 \mathrm{~N}$ for straight abutments for angulated). Subsequently it became splinting for transferring the pillars with acrylic complete combustion, verifying that the individual tray tailored seat properly. In the final printing analogues were placed and, around them, adding to simulate silicone gum in the model. the intermaxillary records were taken and the assembly was held in ASA for making the metal structure. a guide silicone impeller to serve as a guide for future threading contour (Figure 6) previously noted. passive structure adjustment was checked. Simultaneously final printing for ceramic metal bridge in the lower jaw from the workpiece 33 to 47, made by laser fusion technique selective (3D) was taken. Finally he installed a protective splint (Figure 7-9).

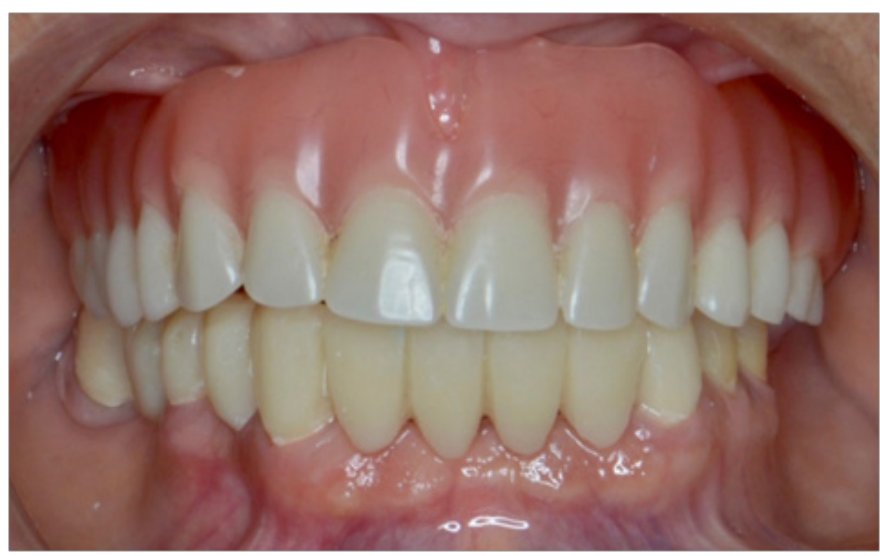

Figure 4

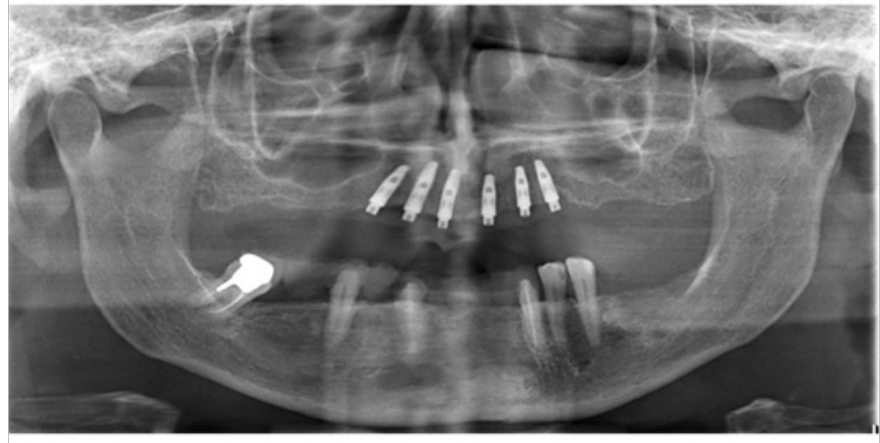

Figure 5

Citation: Estephano PBP, Cisneros OSR, Geldres GE, et al. Rehabilitation implant supported in malocclusion class II with high need for lip support: case report. J Dent Health Oral Disord Ther. 2018;9(4):310-313. DOI: 10.15406/jdhodt.2018.09.00398 


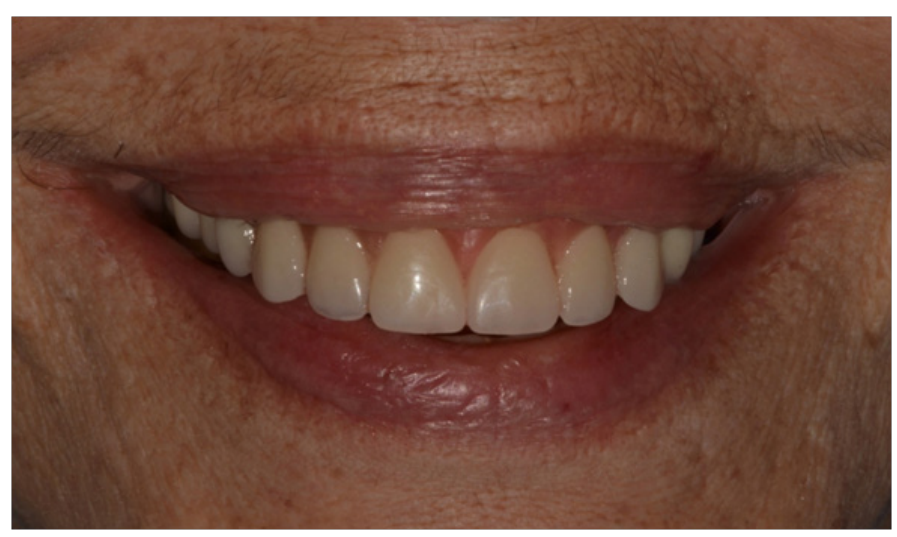

Figure 6

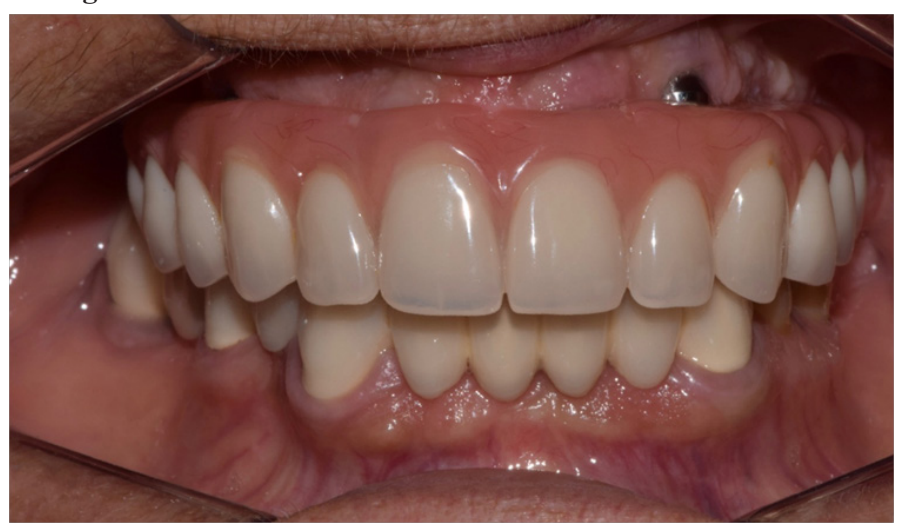

Figure 7

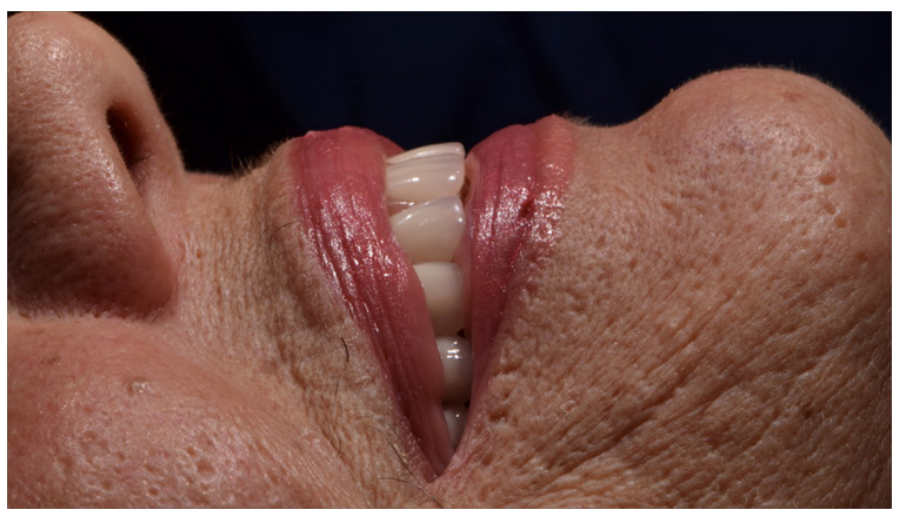

Figure 8

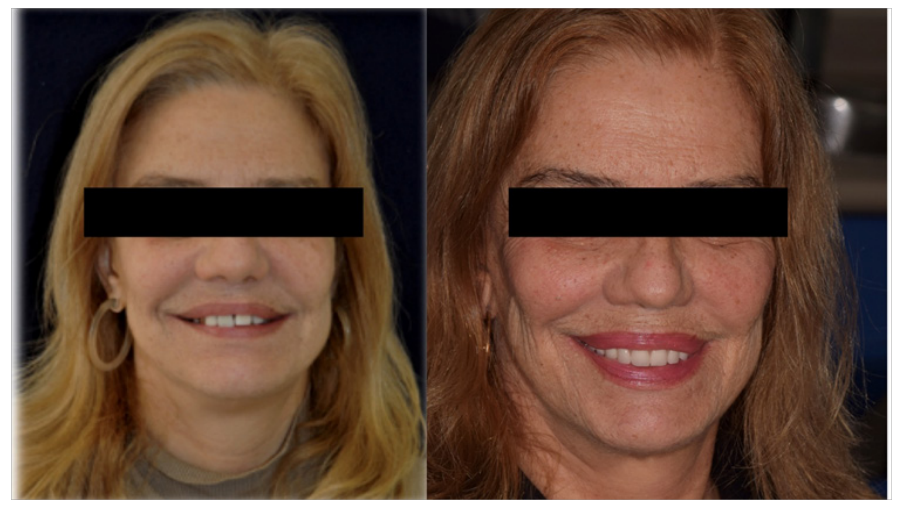

Figure 9

\section{Discussion}

Rehabilitation with the use of hybrid prosthesis improves support, stability and retention. The hybrid prosthesis unlike conventional prosthesis since does not present a buccal flange extending to the groove. ${ }^{1}$ Rehabilitation in patients with poor Class II occlusion is one of the most complicated treatments to manage in oral rehabilitation especially in cases that require a multidisciplinary work involving the use of implants as part of treatment. Patients deep bite class II have some common clinical features: highlight incisor excessive anterior bite deep curve marked spee, wear incisors, upper and lower dental proclination, narrow arches and crowded teeth, type of own occlusion patients malocclusion with class II, hypotonic upper lip, lower lip hypertonic, hypertonic chin, malar depression and convex profile. ${ }^{7}$ It is important to consider during reverse planning the number of implants, the location of the implants, the cantiliever, lip support, the prosthetic space and design of the prosthesis. ${ }^{1-4}$ Reverse planning is to determine the position, number and diameter of implants based on a previously prepared implant-prosthetic design. ${ }^{4}$ This clinical case six implants were placed in the area of premolars, canines and incisors. Heydecke et al. ${ }^{8}$ in 2012 conducted a systematic review, in order to determine the optimal number of implants for fixed prostheses, concluding that treatment with four or six implants is predictable. ${ }^{8}$ The design of the hybrid prosthesis should avoid the accumulation of plaque on the inside, to prevent biological problems as mucositis, periimplantitis or even loss of implants. It is therefore necessary to perform maintenance of the prosthesis every six months, control occlusal splint and control unit. ${ }^{9}$ Murgueitio in 2014 states that all patients with prosthetic hybrid should receive oral hygiene instruction, and also bacterial plaque in a susceptible host is recognized as an etiologic factor of mucositis or periimplantitis. ${ }^{10}$ Thus, He was sensitized to the patient of the importance of monitoring and maintenance of the prosthesis as well as the use and control of protective splint in order to avoid future complications.

\section{Conclusion}

In patients with class II malocclusion should be considered lip support when making hybrid prosthesis, as this malocclusion presents a dynamic movement different from normo-occlusions and demand aesthetic analysis in the previous sector.

\section{Acknowledgements}

None.

\section{Conflict of interest}

The author declares that there is no conflict of interest.

\section{References}

1. Balarezo J. Prosthetic implant in total edentulous.

2. Saluja N, Saluja B, Thapliyal M. A cost-effective approach for hybrid fixed indigenous implant prosthesis-a case report using indident implants. Guident. 2017;11(1):19-22.

3. Papaspyridakos P, Chen C, Chuang S, et al. Implant Loading Protocols for EdentulousPatients With Fixed Prostheses: A Systematic Review and Meta-Analysis. Int J Oral Surg Maxillofac. 2014;29 Suppl:256-270.

4. Four Misch C. Dental implant prosthesis. $1^{\text {st }}$ ed. Spain: Elsevier; 2014.

5. Keith J Ferro. Glossary of Prosthodontic Terms Committee of the Academy of Prosthodontics. Prosthet J Dent. 2017;3(1):7-11. 
6. Drago C, Howell K. Concepts for Designing and Fabricating Metal Implant Frameworks Hybrid Implant Prostheses for. J Prosthodont 2012;21(5):413-424.

7. Pier Romero HH. Clinical characteristics and cephalometric Class II malocclusion. Scientific odous. 2013;14(1):37-45.

8. Heydecke G, Zwahlen M, Nicol A, et al. What is the optimal number of implants for fixed reconstructions: a systematic review. Clin Oral Implants Res. 2012;23 Suppl 6:217-228.
9. Bidra A, Daubert D, Garcia L, et al. Clinical Practice Guidelines for Recall and Maintenance of Patients With Tooth-Borne and Implant-Borne Dental Restorations. Journal of Dental Hygiene. 2016;147(1):67-74.

10. Murgueitio R, Dussán J, Rios M, et al. Avila Visual labels to Facilitate hygiene around implant-supported dental prostheses complete fixed. $J$ Prosthet Dent. 2014;112(6):1588-1590. 